\title{
Toll-like receptor 6 stimulation promotes T-helper 1 and 17 responses in gastrointestinal-associated lymphoid tissue and modulates murine experimental colitis
}

\author{
ME Morgan ${ }^{1}$, PJ Koelink ${ }^{1,4}$, B Zheng ${ }^{1,4}$, MHMGM den Brok², HJG van de Kant ${ }^{1}$, HW Verspaget ${ }^{3}$, \\ G Folkerts ${ }^{1}$, GJ Adema ${ }^{2}$ and AD Kraneveld ${ }^{1}$
}

T-helper 1 and 17 (Th1/Th17) responses are important in inflammatory bowel disease (IBD), and research indicates that Toll-like receptor 6 (TLR6) stimulation leads to Th17 cell development within the lung. The gastrointestinal tract, like the lung, is a mucosal surface that is exposed to bacterially derived TLR6 ligands. Thus, we looked at the effects of TLR6 stimulation on the expression of Th17-, Th1-, and regulatory T-cell-associated transcription factors; ROR $\gamma$ t, T-bet, and Foxp3, respectively; in CD4 + Tcells within gut-associated lymphoid tissue (GALT) in vitro and in vivo. Cells from GALT and spleen were stimulated with anti-CD3 and TLR ligands for TLR1/2 and TLR2/6 (Pam3CSK4 and FSL-1, respectively). FSL-1 was more effective than Pam3CSK4 at inducing Th1 and Th17 responses in the GALT while Pam3CSK4 rivaled FSL-1 in the spleen. TLR6 was further explored in vivo using experimental colitis. TIr6 - / - mice were resistant to colitis, and oral FSL-1 led to more severe colitis in wild-type mice. Similar pro-inflammatory reactions were seen in human peripheral blood mononuclear cells, and TLR6 expression was directly correlated with RORC mRNA levels in inflamed intestines of IBD patients. These results demonstrate that TLR6 supports Th1 - and Th17-skewed responses in the GALT and might be an important target for the development of new medical interventions in IBD.

\section{INTRODUCTION}

Toll-like receptor 6 (TLR6) is a member of the TLR family of pattern recognition receptors. ${ }^{1}$ Like TLR1, it forms a heterodimer with TLR2. ${ }^{2}$ The heterodimer TLR2/6 recognizes diacylated lipopeptides whereas TLR1/2 recognizes triacylated lipopeptides. ${ }^{3,4}$ Lipopeptides are cell wall components of Grampositive bacteria, yeasts, and mycoplasma.

Initial studies on TLR6 have suggested that TLR2/6 stimulation on dendritic cells leads to tolerogenic dendritic cell formation and regulatory T-cell (Treg) development. ${ }^{5,6}$ Tregs have the capacity to suppress the pro-inflammatory activities of other immune cells, and they can differentiate into two main groups based on their expression of the transcription factor, forkhead box p3 (Foxp3). ${ }^{7}$ Foxp3 - Treg, often known as regulatory type $1 \mathrm{~T}$ cells, are induced in the periphery and produce high amounts of interleukin (IL)-10. Foxp3 + Treg, on the other hand, may be induced or thymus-derived and use additional suppression mechanisms.

Recently, contradictory results were published that demonstrated that TLR6 could support the development of T-helper 17 (Th17) cells in lung, which were protective against fungal infection. ${ }^{8}$ Th17 cell responses are especially important for the control of extracellular bacterial and fungal pathogens and are particularly well known for their ability to stimulate the

${ }^{1}$ Division of Pharmacology, Utrecht Institute for Pharmaceutical Sciences, Faculty of Science, Utrecht University, Utrecht, The Netherlands. ${ }^{2}$ Tumor Immunology Laboratory, Radboud University Nijmegen Medical Centre, Nijmegen, The Netherlands and ${ }^{3}$ Department of Gastroenterology and Hepatology, Leiden University Medical Center, Leiden, The Netherlands. Correspondence: AD Kraneveld (a.d.kraneveld@uu.nl)

${ }^{4}$ These authors contributed equally to this work. 
accumulation of neutrophils. ${ }^{9}$ Th17 cells are characterized by the master transcription factor, retinoic acid-related orphan receptor $\gamma \mathrm{t}(\mathrm{ROR} \gamma \mathrm{t})$ and the production of IL-17A, IL-17F, IL-22, IL-26, tumor necrosis factor $\alpha$, and granulocyte macrophage colony-stimulating factor. Under pro-inflammatory conditions, with high amounts of IL-23 and IL-1 $\beta$, they also produce interferon $\gamma(\operatorname{IFN} \gamma){ }^{10}$

Genome-wide association scan data indicate a role of Th17 cells in inflammatory bowel disease (IBD) ${ }^{11}$ and Th17 cells are increased in patients with a magnified activation state. ${ }^{12-14}$ This is in addition to the classical T-cell subset associations of the two main forms of IBD: Th1 with Crohn's disease and Th2 with ulcerative colitis. ${ }^{15}$ Crohn's disease, in particular, appears to be mediated by Th1/Th17 responses, ${ }^{15}$ including highly inflammatory Th17 cells that produce IFN $\gamma .{ }^{12,16}$

As TLR6 is involved in Th17 induction in the lung, ${ }^{8}$ we considered that TLR6 might be involved in modulating Th17 responses in IBD. We found that TLR6 stimulation of murine gut-associated lymphoid tissue (GALT) cells was more effective than Pam3CSK4 (TLR1/2 ligand) at inducing Th1/ Th17 responses in vitro. Moreover, Tlr6-/ - mice were protected against colitis while the addition of TLR6 ligands during colitis led to worsened disease and increased Th17 responses after disease resolution. TLR6 stimulation may be important in controlling Th1/Th17-mediated inflammation in IBD patients.

\section{RESULTS}

TLR6 is expressed in the intestines of IBD patients and mice with experimental colitis

Researchers have reported a role for TLR6 in the development of Th17 cells at the lung mucosa. ${ }^{8}$ Therefore, we investigated the expression of TLR6 mRNA and protein in inflamed intestinal tissues. Immunofluorescence staining showed that TLR6 was expressed in the intestine by both crypt epithelial and non-epithelial cells, and TLR6 + cells were present in IBD intestinal biopsies (Figure 1a). TLR6 and RORC mRNA were also detected in both patient and control intestines (Figure 1b). Although the mRNA levels were not significantly changed in IBD patients, the levels of the two genes were significantly correlated (Figure 1c), suggesting increased TLR6 expression has a relationship with the Th17-associated master transcription factor $R O R C$ in the intestine.

To determine Tlr6 mRNA expression in the murine colon, we isolated mRNA from colon at both the distal (rectum) and proximal (cecum) ends during intestinal inflammation (day 7) in the dextran sodium sulfate (DSS)-induced colitis model. In DSS colitis, the disease manifests more strongly at the distal end. Although both control and DSS-treated mice expressed Tlr6 in the colon, during colitis Tlr6 mRNA was significantly increased in the inflamed distal region of the colon (Figure 2a). The increased expression of TLR6 protein was confirmed by immunoblot (Figure 2b). As expected, we observed a double

a
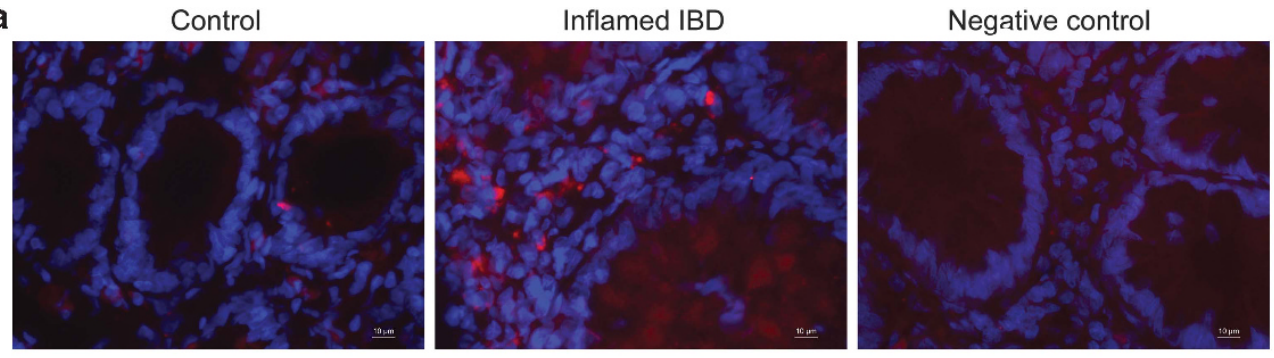

b
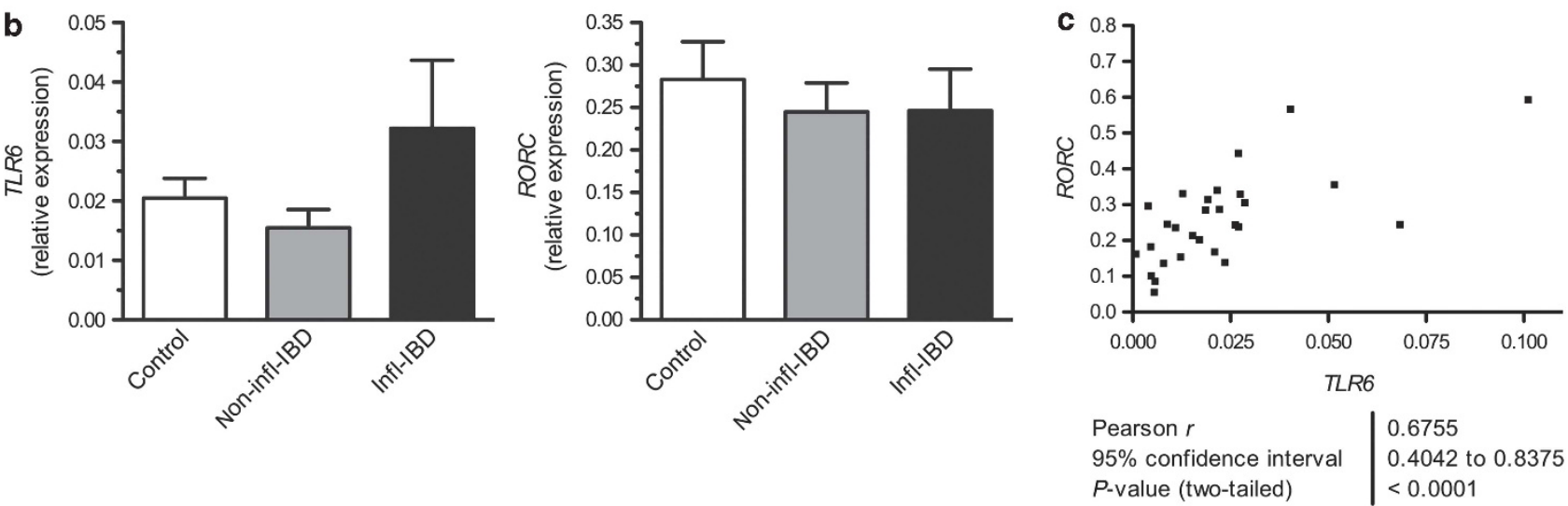

Figure 1 Toll-like receptor 6 (TLR6) is expressed during inflammatory bowel disease (IBD). (a) Immunofluorescent staining of TLR6 in intestinal tissues obtained from a control (Control) and an IBD patient (Inflamed IBD). Negative control shows background stain without the primary antibody. Representative stains are shown for $n=3$ controls and IBD patients. Red staining shows TLR + cells, and blue shows nucleic acids (cell nuclei). Photomicrographs were taken at $\times 400$ magnification. (b) Relative expression of RORC and TLR6 was determined for RNA obtained from colon carcinoma patients (control, $n=10$ ), non-inflamed regions of IBD patient intestinal tissue (non-infl-IBD, $n=10$ ) and matched inflamed regions of IBD patient intestines (infl-IBD). Data are presented as mean + s.e.m. The measurement was performed twice independently. (c) A significant correlation was found between the mRNA levels of RORC and TLR6 in colon samples obtained from both control and IBD patient material ( $n=28)$. 

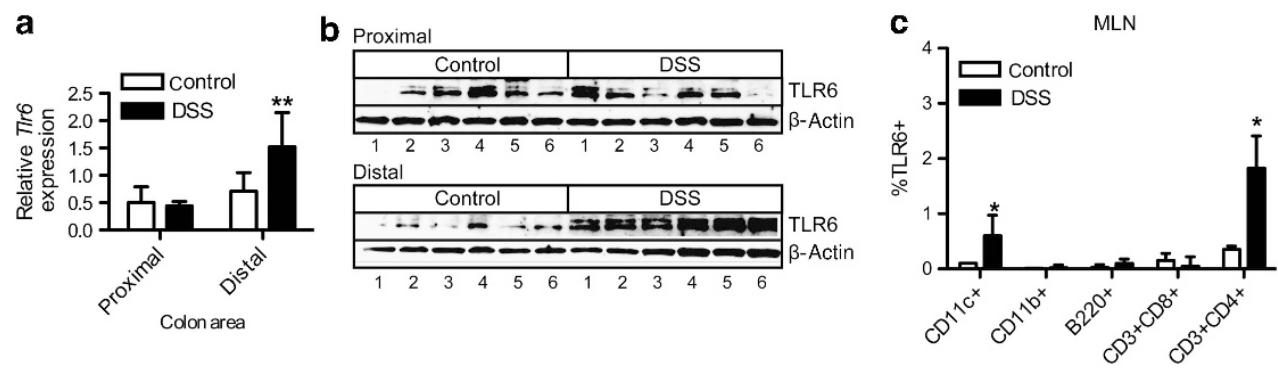

Figure 2 Toll-like receptor 6 (TLR6) expression is increased during experimental colitis. (a) Distal and proximal regions of colon tissues isolated from control and dextran sodium sulfate (DSS)-treated mice were analyzed for TIr6 $(n=6)$. Values are presented as relative to the household gene Rps13. (b) Immunoblot for TLR6 protein content in distal and proximal colon tissues of control and DSS-treated mice $(n=6)$. The double bands are in accordance with the staining pattern shown by the manufacturer of the TLR6 antibody. Beta-actin staining was used as a loading control. (c) mesenteric lymph node $(\mathrm{MLN})$ cells from control and DSS-treated mice were stained $(n=4)$ with either an antibody for TLR6 or a matched isotype control. The percentage of TLR6 staining was determined for various immune cells. Matched isotype values were first subtracted. Data are presented as mean + s.e.m. $P$-values considered as significant are indicated as ${ }^{*}<0.05,{ }^{* *}<0.01$.

band of $\sim 100 \mathrm{kD}$, demonstrating that TLR6 is upregulated in the colon during colitis. To determine which immune cells express TLR6, mesenteric lymph node (MLN) cells were isolated from control and DSS-treated mice and were examined for TLR6 expression using flow cytometry. TLR6 expression was low in immune cells taken from control mice (Figure 2c). In DSS-treated mice, TLR6 expression was significantly upregulated in CD11c + and CD3 + CD4 + cells.

\section{TLR6 stimulation increases ROR $\gamma$ t expression in the GALT}

We explored TLR1/2 and TLR2/6 stimulation in the context of murine GALT by looking at the effect of TLR ligands (TLRLs) on CD4 + T-cell responses in Peyer's patches (PPs) and MLN. Spleen was also included as a control tissue. Th17-, Th1-, and Treg-associated responses were measured by master transcription factor expression (ROR $\gamma \mathrm{t}$, T-bet, and Foxp3, respectively). $\mathrm{CD} 4+\mathrm{ROR} \gamma \mathrm{t}+\mathrm{T}$-cell expression of IL-17A was first confirmed in MLN cells (Figure 3a). Although not all $\mathrm{CD} 4+\mathrm{ROR} \gamma \mathrm{t}+\mathrm{T}$ cells expressed IL-17A $(\sim 20 \%)$, the IL-17A expression was constrained to the CD4 + ROR $\gamma \mathrm{t}+$ T-cell population.

The expression of ROR $\gamma \mathrm{t}$ and Foxp3 in activated CD4+ CD69 + T cells was measured in the GALT (MLN and PP) and spleen after stimulation with anti-CD3 and TLRLs. Stimulation with FSL-1 in GALT cells led to a significant increase in ROR $\gamma \mathrm{t}+$ Foxp3 - T cells within the CD $4+\mathrm{CD} 69+$ population that was not observed in the other conditions (Figure $\mathbf{3 b}$ and c). Parallel reductions in the percentage of ROR $\gamma \mathrm{t}$ Foxp $3+\mathrm{T}$ cells in the FSL-1-treated GALT cells were also noted. The effect of FSL-1 was also observed in spleen cells (Figure 3c) and human peripheral blood mononuclear cells (PBMCs) (Supplementary Figure $\mathbf{1 A}$ online). Pam3CSK4 had little effect on GALT cells except lowering ROR $\gamma$ t-Foxp3 + T cells in the MLN. However, Pam3CSK4 increased the percentage of ROR $\gamma \mathrm{t}+$ Foxp $3-\mathrm{T}$ cells in the spleen (Figure 3c).

Loss of TLR6 expression eliminated all FSL-1-mediated transcription factor changes (Figure 3d). Its effect on the response caused by PAM3CSK4, in contrast, was limited.
Unlike ROR $\gamma \mathrm{t}$, expression of the Th1 transcription factor, T-bet, was not stimulated by the addition of TLRLs during the stimulation of MLN cells with anti-CD3. It also remained unchanged in CD4 + T cells in Tlr6 - / - mice (Figure 4a-d).

\section{T-cell stimulation combined with FSL-1 increases both IFN $\gamma$} and IL-17A secretion in the GALT

To further investigate influences on T-cell polarization during stimulation with anti-CD3 and TLRLs, we measured IFN $\gamma$, IL-17A, IL-10, IL-4, IL-2, IL-6, and transforming growth factor $\beta$ (TGF $\beta$ ) in the supernatants after $48 \mathrm{~h}$ of culture. IL- 4 was hardly detectable in all of the cultures (data not shown). In GALT cultures, the addition of FSL-1 during anti-CD3 stimulation led to significant increases in the production of IFN $\gamma$ and IL-17A that were not seen after stimulation with Pam3CSK4 (Figure 5). In PP cells, Pam3CSK4 and FSL-1 both induced a significant increase in IL-10, a trend also seen in MLN. FSL-1 significantly increased the levels of IL-2 in the MLN and PP, while Pam3CSK4 had only the same response in the MLN. Interleukin- 6 was increased by both TLRLs in the GALT, while TGF $\beta$ levels remained the same in all conditions.

The spleen cells, in general, produced far higher amounts of cytokines than the GALT cells when stimulated with anti-CD3 and TLRLs. All cytokines, except TGF $\beta$, appeared to increase. Significant changes were measured for IFN $\gamma$ after FSL-1 treatment and IL-6 after Pam3CSK4 (Figure 5). Within the spleen and human PBMCs (Supplementary Figure 1B), FSL-1 and Pam3CSK4 performed almost identically with both TLRLs causing significant and not quite significant increases in the cytokines tested.

\section{FSL-1 leads to increased Th1 and Th17 cells in GALT long-term cultures}

The previous results were after short 48 -h stimulations. Early changes in transcription factor expression and cytokines may not be representative of fully differentiated and expanded effector T cells. Therefore, MLN and spleen cells were stimulated with anti-CD3 in combination with the TLRLs and expanded for 7 days in culture. Restimulation with PMA/ ionomycin revealed that both TLRLs led to significantly 
a
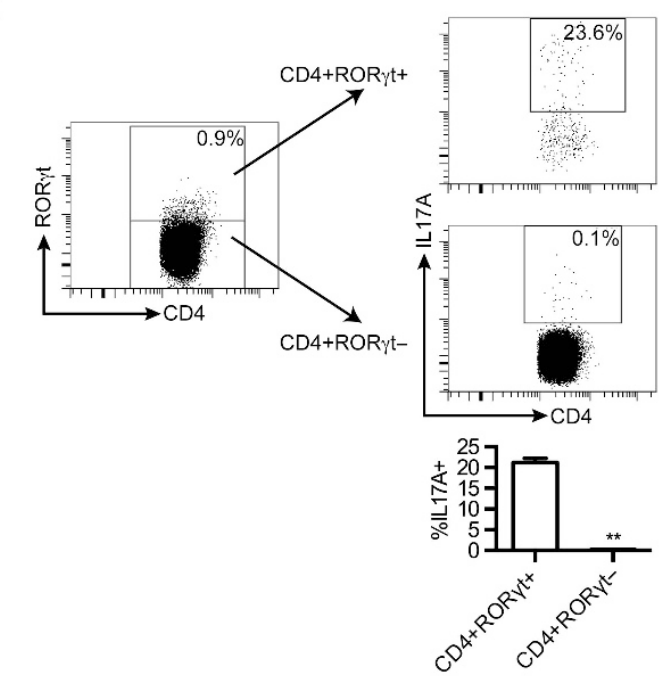

b

None
No

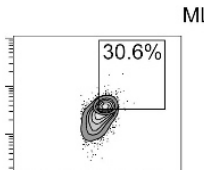

MLN
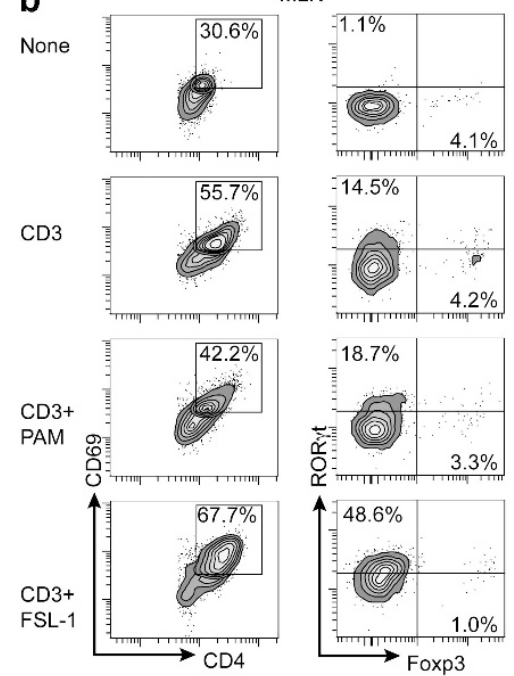

c
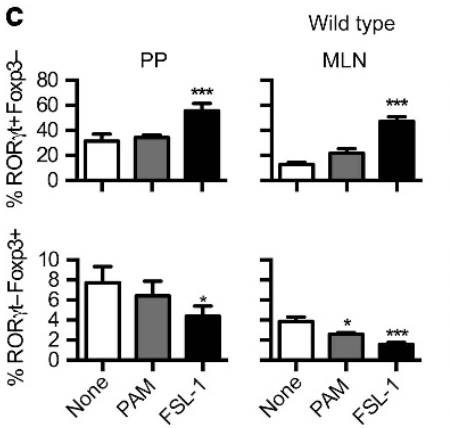
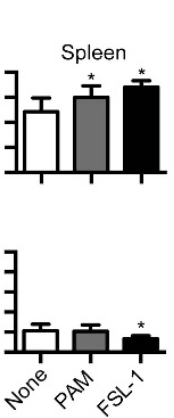

d

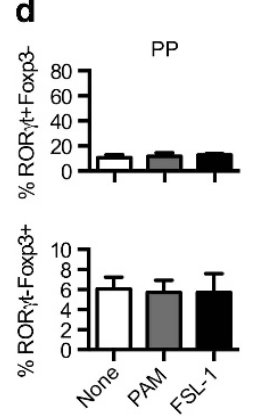

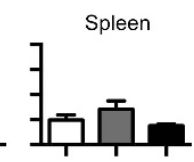

Figure 3 FSL-1 stimulation of murine gut-associated lymphoid tissue (GALT) cells increases ROR 7 t expression and lowers Foxp3 expression. (a) Cells were isolated from mesenteric lymph node (MLN) and stimulated with PMA/ionomycin $(n=6)$ and the numbers of IL-17A + cells in the CD4 + ROR $\gamma \mathrm{t}+$ and CD4 + ROR $\gamma \mathrm{t}-\mathrm{T}$ cells population determined. Representative plots are shown for a single mouse. (b) Left column: percentages CD4 + CD69 + T cells from total MLN cells after the indicated stimulation. Right column: ROR $\gamma \mathrm{t}$ and Foxp3 staining of the CD4 + CD69+ cells in the left column. Plots are representative of the data presented in part c. (c) Cells isolated from the indicated lymphoid tissues from wild-type mice were stimulated with anti-CD3 and TLRLs. Percentages of ROR $\gamma \mathrm{t}+$ Foxp3 - and ROR $\gamma \mathrm{t}$-Foxp3 + T cells were determined from the gated CD4 + CD69 + T-cell population ( $n=4$, pooled from two independent experiments). (d) Cells isolated from lymphoid tissues of TIr6 $-/-$ mice were stimulated and analyzed as in part C $(n=3)$. Data are presented as mean + s.e.m. $P$-values considered as significant are indicated as ${ }^{*}<0.05,{ }^{* *}<0.01$ and ${ }^{\star * *}<0.001$.

increased amounts of CD4 + IL-17A + T cells (Th17) within MLN cell suspensions (Figure 6a). However, FSL-1 uniquely led to magnified percentages of CD $4+$ IFN $\gamma+$ T cells (Th1) in MLN cell cultures. Neither TLRL induced CD4 + IL-10 + cells. In the spleen cell cultures, both TLRLs caused similar increases in CD $4+\mathrm{IFN} \gamma+\mathrm{T}$ cells with $\sim 80 \%$ of the CD $4+\mathrm{T}$ cells expressing IFN $\gamma$. Though the percentage of Th17 cells appeared to increase in FSL-1-treated spleen cultures, only Pam3CSK4 treatment led to significant increases. Pam3CSK4 treatment also increased the percentage of CD4 + IL-10 + T cells, while FSL-1 decreased them.

It has been reported that $\mathrm{CD} 4+\mathrm{T}$ cells double positive for both IFN $\gamma$ and IL-17A are particularly potent autoimmune Th17 cells that arise when Th17 are exposed to high IL-23 and IL- $1 \beta .^{10}$ Therefore, we examined if the populations of CD4+ IFN $\gamma+$ IL-17A + T cells were also changed in the cultures. These rare cells increased significantly in the FSL-1-treated MLN cultures and were not affected by Pam3CSK4 treatment (Figure 6b). In expanded spleen cultures, Pam3CSK4, but not
FSL-1 treatment, significantly increased the $\mathrm{CD} 4+\mathrm{IFN} \gamma+$ IL-17A + T-cell population.

TIr6 - I - mice have lowered Th1 and Th17 responses in the GALT and are protected against colitis

Tlr6 - / - mice have less Th17 cells in the lung. ${ }^{8}$ The possibility existed that lowered Th17 numbers would be found in the GALT as well. To determine if this was the case, T-cell subsets were examined in the MLN and PPs of Tlr6 - / - mice. In both tissues, significant reductions of CD4 + ROR $\gamma \mathrm{t}+$ Foxp3 $\mathrm{T}$ cells were observed as compared with wild-type controls while the rest remained unchanged (Figure $7 \mathbf{a}$ and $\mathbf{b}$ ). Owing to the changes in the Th17 populations, we speculated that Tlr6 - / - mice could be protected against DSS-induced colitis. Tlr6 - / - mice were less susceptible to colitis than wild types, as judged by the disease activity index (Figure 8a). This difference was also observed in the colon length (Figure 8b). Both Tlr6-/ - mice and wild-type mice had shortened colons after DSS exposure; however, the colons of the DSS-treated wild 
a
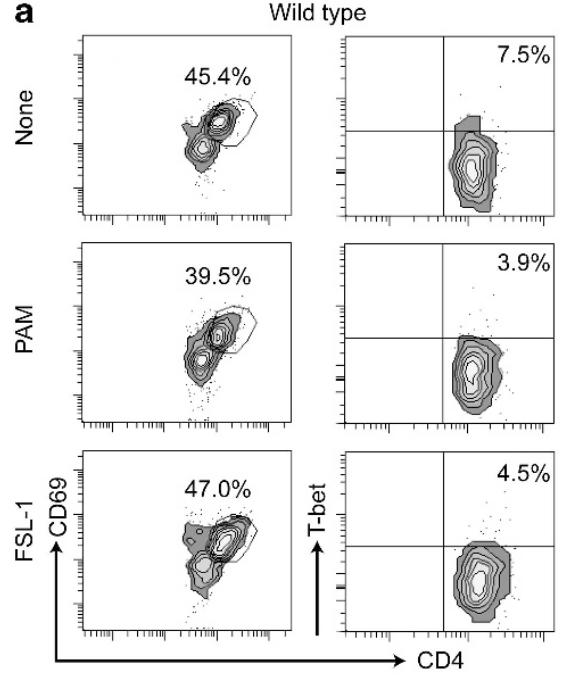

b
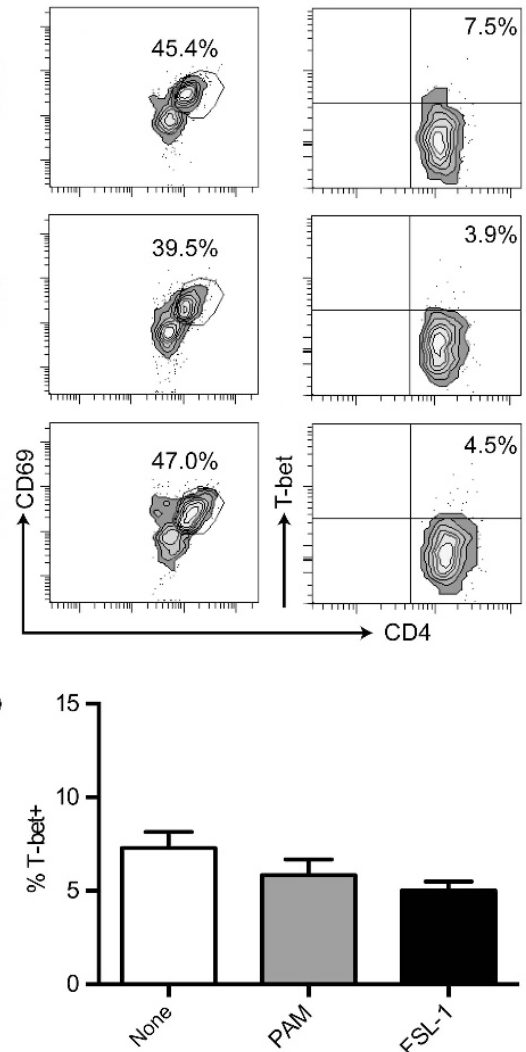

C
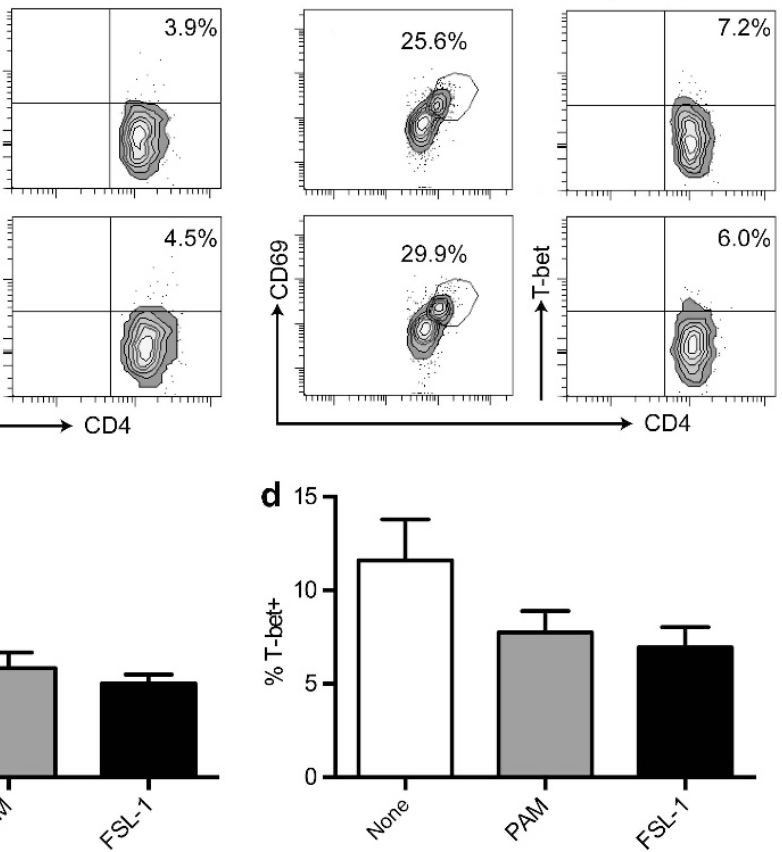

Figure 4 TLRL stimulation of murine mesenteric lymph node (MLN) cells does not affect T-bet expression. Wild-type (a and $\mathbf{b})$ and T/r6 $-/-(\mathbf{b}$ and $\mathbf{c})$ MLNs were stimulated with TLRLs and anti-CD3. T-bet was measured after $48 \mathrm{~h}$ of stimulation. None, anti-CD3 alone; PAM, Pam3CSK4 and anti-CD3; and FSL-1, FSL-1 and anti-CD3. (a and c) Left column: percentages CD4 + CD69 + T cells from total MLN cells after the indicated stimulation. Right column: T-bet and CD4 staining of the CD4 + CD69 + cells in the left column. T-bet plots are representative of the data $(n=5)$ presented in parts $\mathbf{b}$ and $\mathbf{d}$. Data are presented as mean +s.e.m.

type mice were significantly shorter than the colons of the DSStreated Tlr6 - / - mice.

An investigation of the transcription factor expression and cytokine production in GALT CD4 + cells revealed that during colitis, CD4 + ROR $\gamma \mathrm{t}+$ Foxp3- T cells remained significantly reduced in Tlr6-/- mice compared with wild types (Figure 8c and d). Significant and almost significant reductions of $\mathrm{CD} 4+\mathrm{T}$-bet + cells were also observed in the MLN and PP of Tlr6-/- mice. Lowered CD4+ ROR $\gamma \mathrm{t}-$ Foxp3 + populations were also observed in the MLN, but not in the PP.

\section{Oral FSL-1 increases experimental colitis severity and residual Th17-associated responses}

Because TLR6 expression was increased in the colon during DSS colitis, we speculated that in vivo treatment with the TLR6 ligand, FSL-1, during colitis would lead to changes in the disease progression and associated Th1 and Th17 responses. FSL-1, Pam3CSK4, or saline in combination with ovalbumin (OVA) were orally administered on day 4,5 , and 6 after the start of DSS water to both healthy and DSS-treated mice (Figure 9a). Due to the risk that oral TLRL treatment might lead to extremely severe disease, a mild form of DSS colitis was induced. Analysis of the weight scores showed that only FSL-1-treated mice experienced a significantly sharper decrease in weight on day 7 as compared with the DSS controls at these conditions (Figure 9a).

To observe changes in the T-cell compartments after inflammation, mice were sacrificed on day 14 , and cytokine expression in CD4 + cells was examined in the MLN and spleen. FSL-1- and DSS-treated mice had significantly increased amounts of CD4 + IL-17A + cells in the MLN relative to the mice treated with just DSS (Figure 9b). Expression of IFN $\gamma$ was low in the MLN, and no appreciable numbers of CD4 + IL$17 \mathrm{~A}-\mathrm{IFN} \gamma+$ and $\mathrm{CD} 4+\mathrm{IL}-17 \mathrm{~A}+\mathrm{IFN} \gamma+$ were noted, preventing analysis (data not shown). Although cytokines were measured in the spleen, there were no differences measured between the groups (data not shown).

Further analysis of the T-cell response using anti-CD3 stimulation and transcription factor staining revealed that FSL-1- and DSS-treated animals had approximately four times as many potential Th17 cells within the total CD $4+\mathrm{T}$ cells as compared with the untreated DSS controls in the spleen while Treg populations remained unchanged (Figure 9c). In the MLNs, similar changes were observed, however, they were not quite significant. Similar responses were also observed for antigen-specific $\mathrm{CD} 4+\mathrm{T}$-cell responses directed against the 
PP
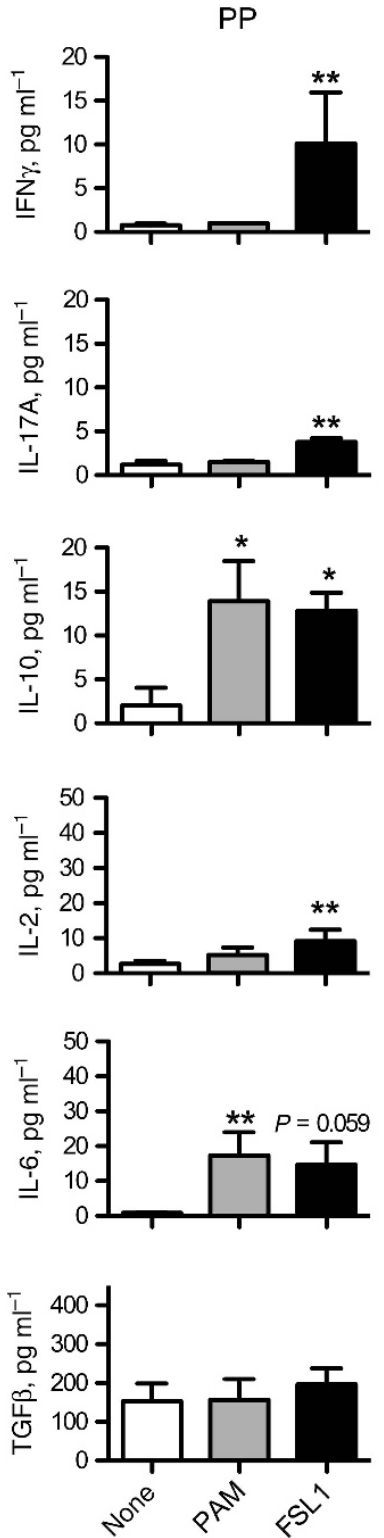

MLN
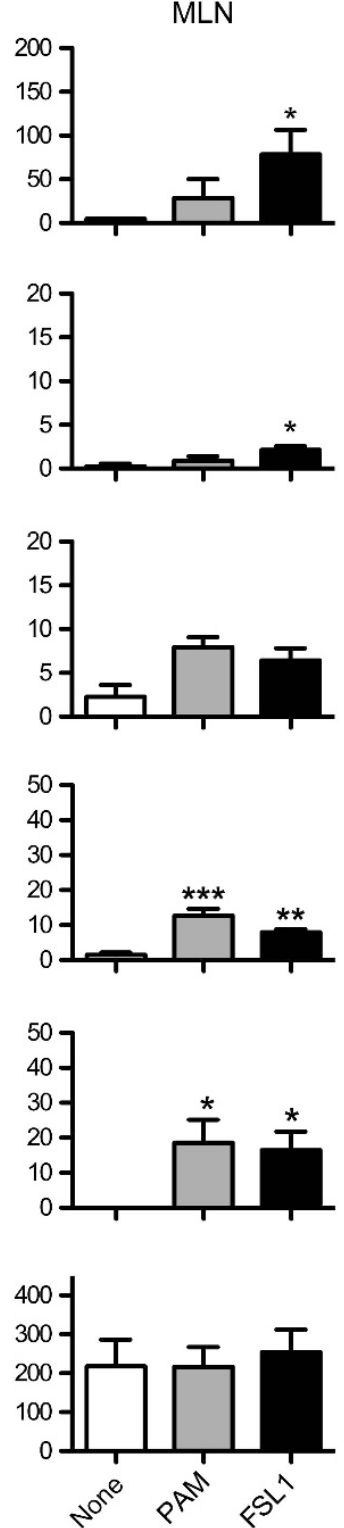
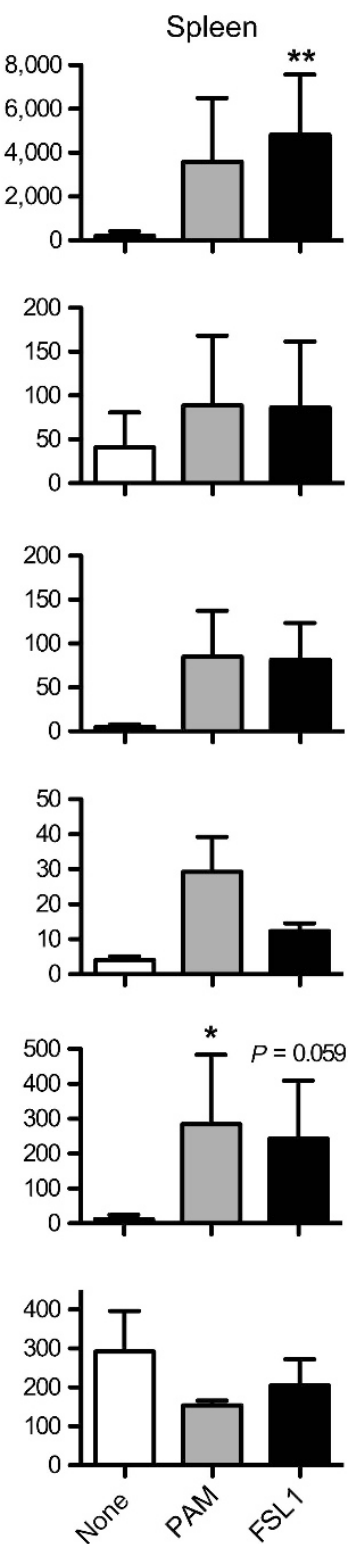

Figure 5 T-cell stimulation with anti-CD3 and FSL-1 leads to increased IFN $\gamma$, IL-17A secretion in gut-associated lymphoid tissue (GALT). Cells isolated from murine Peyer's patches (PPs), mesenteric lymph nodes (MLNs), and spleens were stimulated with anti-CD3 and TLRLs ( $n=4$ ). After $48 \mathrm{~h}$, supernatants were isolated and analyzed for cytokine content. The cytokines measured and the units are given in the $y$-axis. Data are presented as the mean + s.e.m. $P$-values considered as significant are indicated as ${ }^{*}<0.05,{ }^{\star *}<0.01$, and ${ }^{* \star *}<0.001$.

tracking antigen OVA, which was administered simultaneously with the TLRLs (Supplementary Figure 2).

\section{DISCUSSION}

The role of TLR6 at the mucosal interface is not well understood. Studies by DePaolo et al. ${ }^{5}$ demonstrate that TLR2/6 stimulation of dendritic cells, both in vitro and in vivo, is associated with the formation of suppressive immune responses. Recently, the same group also found lowered regulatory responses and enhanced Th1 and Th17 responses in TLR6 $-/-$ mice $^{6}$ during Yersinia enterocolitica infection, supporting their previous findings. In contrast, research on the lung mucosa found conflicting data. Protective Th17 responses were impaired in TLR6 - / - mice during Saccharopolyspora rectivirgula and Aspergillus fumigatus infections of the lung. . $^{8,17}$ Moreover, the administration of macrophage-activating lipopeptide-2 (another TLR2/6 ligand) to rat lung caused the influx of immune cells. ${ }^{18}$ There are also conflicting reports about the effects of TLR2/6 stimulation on human Treg. Some studies show that TLR2/6 ligands suppress Treg function, like TLR1/2 ligands, while others show that it is ineffective. ${ }^{19,20}$

Our results show that there is a relationship between TLR6 stimulation in the GALT, and the induction of Th1/Th17 responses, which is not shared by TLR1/2. Even though Pam3CSK4 stimulation leads to responses in the GALT, they are relatively milder than those induced by FSL-1 and do not 

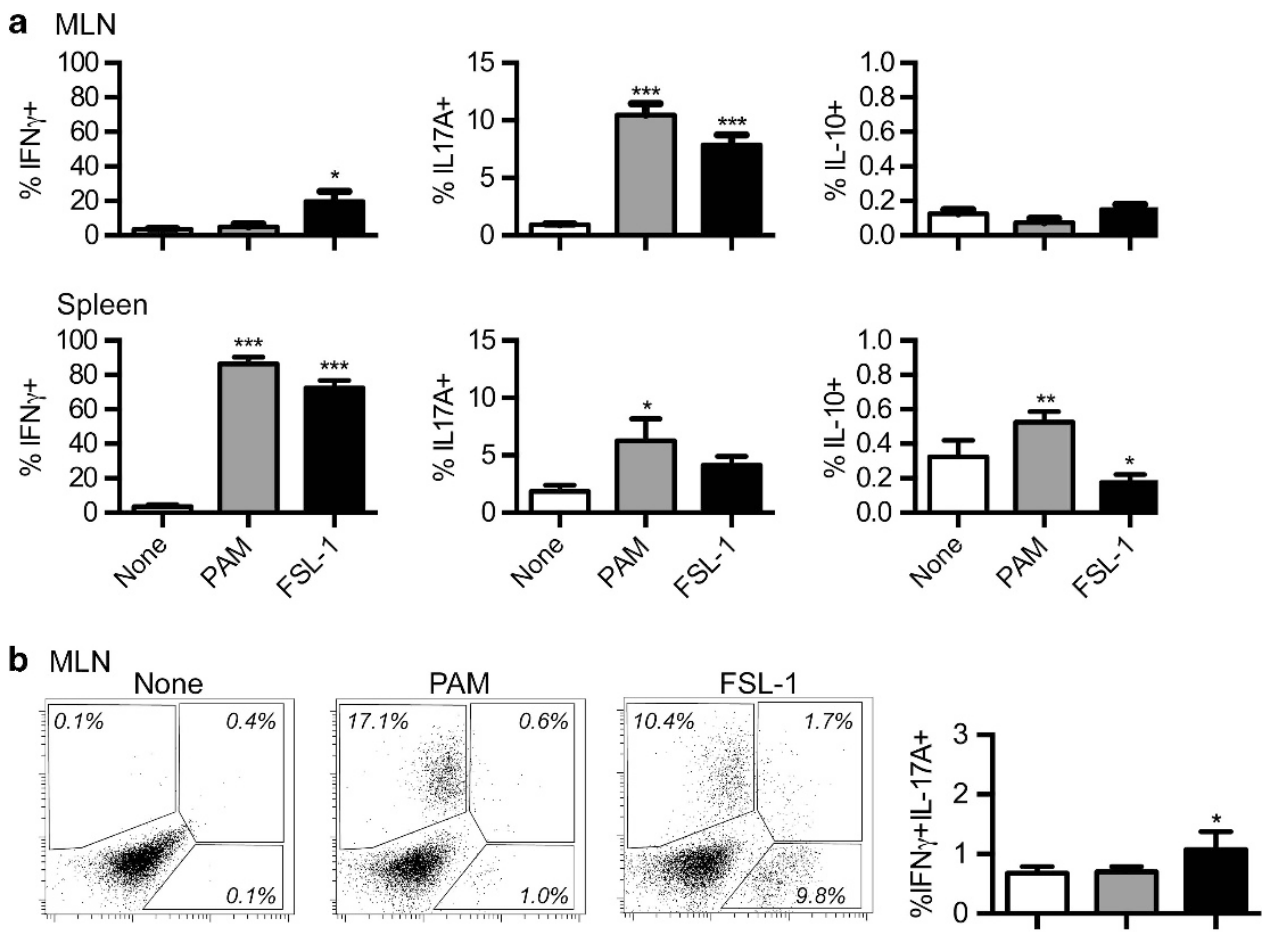

Spleen
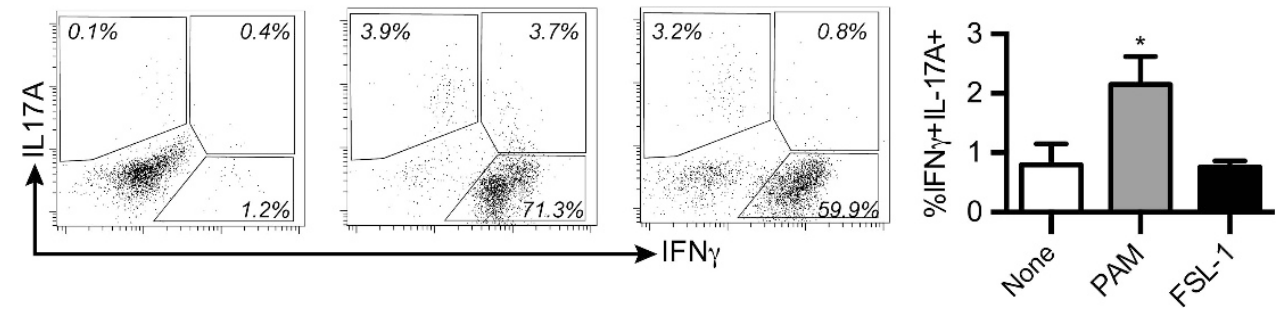

Figure 6 FSL-1 leads to increased Th1 and Th17 cells in extended mesenteric lymph node (MLN) cultures. Cells isolated from the MLNs or spleens $(n=4)$ were stimulated with anti-CD3 and TLRLs for 7 days followed by PMA/ionomycin stimulation. (a) Percentages of cytokine-positive CD4 + cells are indicated. (b) Percentages of CD4 + IFN $\gamma+$ IL-17A + cells are shown in the column figure on the right. Representative FACS plots for a single mouse are also shown. Data in column graphs are presented as the mean + s.e.m. $P$-values considered as significant are indicated as ${ }^{*}<0.05,{ }^{* *}<0.01$, and ${ }^{* * *}<0.001$.

support Th1. In contrast, Pam3CSK4 appears superior to FSL-1 at inducing Th1/Th17 in the spleen. Deeper investigation of TLR6 in vivo further supported the in vitro findings for TLR6; TLR6 stimulation worsens colitis development and is involved with Th1/Th17 induction. Furthermore, TLR6 expression is increased in the distal colon during colitis, where inflammation is the highest, ${ }^{21}$ and TLR6 is expressed in the inflamed intestines of IBD patients where it also correlates with RORC expression. Taken together, this indicates that TLR6 is an interesting player in intestinal inflammation.

Performing re-stimulations with anti-CD3 and TLR2/6 or TLR1/2 ligands showed that FSL-1, but not Pam3CSK4, induced ROR $\gamma \mathrm{t}$ and reduced Foxp3 in GALT cell suspensions after $48 \mathrm{~h}$ of culture. As CD4 + T cells do express TLR6, this effect could be mediated by direct signaling, or it could be mediated by cytokine release from other immune cells. Our results suggest that the latter could be a possibility. Th17 cells require expression of the transcription factor, ROR $\gamma \mathrm{t}^{22}$ Th17 differentiating conditions (anti-CD3 with low IL-2, IL-4, IFN $\gamma$, and high IL- 6 and TGF $\beta$ ) increase Rorc mRNA after 25 h. ${ }^{23}$ In our FSL-1-treated cultures, IL-4 and IL-2 were both at low concentrations; TGF $\beta$ was present, and both IFN $\gamma$ and IL-6 were increased. IL-6 induces STAT3 (signal transducer and activator of transcription 3), which is needed for Rorc transcription. ${ }^{24}$ STAT3 also induces the loss of FOXP3 in human natural Tregs, ${ }^{25}$ which was also observed. Despite high concentrations of IFN $\gamma$ (which is not necessarily detrimental to Th17 induction ${ }^{26}$ ), the environment was, at a cytokine level, conducive to Th17 development and detrimental to Treg.

Despite the lack of changes in T-bet expression in GALT cells at $48 \mathrm{~h}$ of culture, large amounts of IFN $\gamma$ were produced as well as other pro-inflammatory cytokines. As $48 \mathrm{~h}$ is too short of a period for naïve $\mathrm{T}$ cells to be stimulated, differentiate, and produce their own cytokines; the source must be other cells found in our cell suspensions. Existing memory Th1 cells are likely candidates, and it is known that they produce IFN $\gamma$ and IL-10 when costimulated with TLR2 ligands. ${ }^{27}$ Other options 

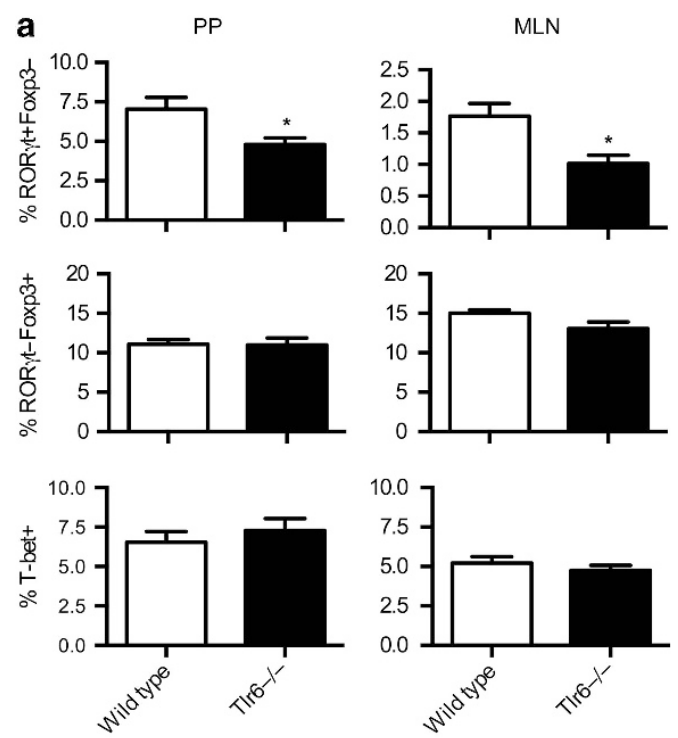

b
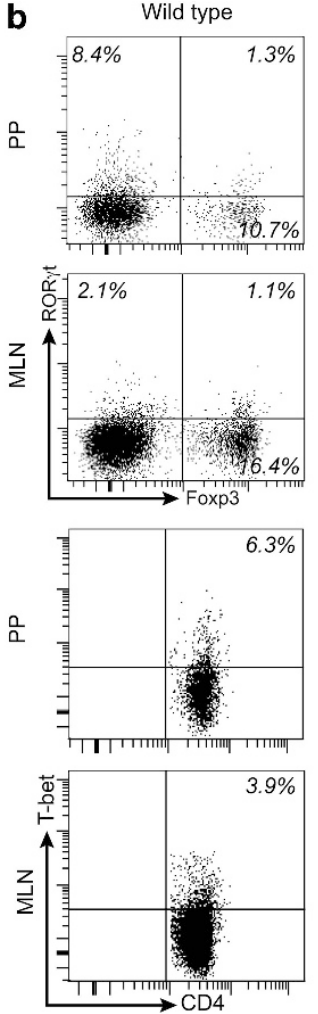
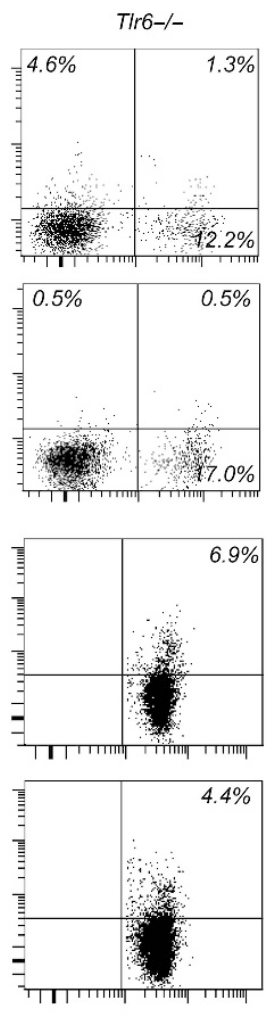

Figure 7 TIr6 - / - mice have lower amounts of CD4 + ROR $\gamma \mathrm{t}+$ cells. (a) Gut-associated lymphoid tissue (GALT) cells were isolated from both TIr6 - / - and wild-type mice $(n=6)$. ROR $\gamma \mathrm{t}$, Foxp3, and T-bet expression were analyzed within the CD4 + T-cell population. (b) Representative plots of a single mouse are shown for the transcription factor staining. Data are given as mean + s.e.m. $P$-values considered as significant are indicated as ${ }^{*}<0.05$. PPs, Peyer's patches.

are memory CD $8+\mathrm{T}$ cells,${ }^{28}$ innate lymphoid cells, ${ }^{29}$ dendritic cells, ${ }^{30}$ and macrophages. ${ }^{31}$

To further determine the long-term effects on T-cell differentiation, extended cultures were performed with the TLRLs. In MLNs, Pam3CSK4 induced CD4 + IL-17A + cells just as well as FSL-1 but, unlike FSL-1, did not induce CD4 + IFN $\gamma+$ cells. Looking at the cytokines produced during the first $48 \mathrm{~h}$ shows that MLN stimulated with anti-CD3 and Pam3CSK4 produced significantly higher levels of IL-6. As IL-6 combined with TGF $\beta$ is needed to differentiate Th17 cells, the development of Th17 is to be expected. The response is not, however, entirely the same as that with FSL-1, which also induced IFN $\gamma / \mathrm{IL}-17 \mathrm{~A}$ double-positive cells. These cells are indicative of a highly proinflammatory cytokine milieu and promote intestinal inflammation found in IBD. ${ }^{12,16}$ The main difference between the two stimulations was the presence of IFN $\gamma$ in the FSL- 1 cultures. The presence of IFN $\gamma$ supports Th1 development ${ }^{32}$ and also promotes Th17 responses. ${ }^{26}$ This could be the main reason that FSL-1 leads to Th1/Th17 responses in the GALT.

We observed clear differences between Pam3CSK4 and FSL-1 in the GALT. This does not exclude an important role for TLR1/2 in intestinal inflammation, but does suggest that it is different than that of TLR2/6. Our results and studies by DePaolo et al. ${ }^{6}$ indicate that TLR $1 / 2$ is responsible for intestinal Th17 responses. Still, TLR1/2 stimulation is more potent in the spleen than GALT, inducing both Th1 and Th17. This tissue specific response is an important consideration for future work on TLRLs and may offer some explanation to conflicting data in previous publications.

To investigate TLR6 in intestinal inflammation, DSS colitis was induced in Tlr6 - / - mice. Our experiments showed that these mice were partially protected from the disease. Interestingly, Tlr6 - / - mice have reduced numbers of Th17 cells as compared with the wild-type mice, and they remain low even during colitis. During colitis, these mice also had fewer CD4 + T-bet + cells and reduced Treg. Although the loss of Treg is puzzling, the reductions in Th1/Th17 may have influenced the severity of disease.

To learn more about the fate of $\mathrm{CD} 4+\mathrm{T}$ cells primed during DSS-induced colitis, FSL-1 or Pam3CSK4 were orally administered along with the tracking antigen OVA during the induction of colitis in wild-type animals. Significantly increased Th17 responses in the FSL-1- and DSS-treated mice were found in the MLNs and spleen using several different assays. This is particularly striking as these responses were measured 7 days after DSS treatment was stopped. In contrast, residual Th1 responses were not measured. DSS colitisassociated T-cell responses within the spleen after disease resolution are not unusual. It has been observed that after DSS colitis heals, there is a striking increase of CD4 $+\mathrm{T}$ cells in the spleen, while the percentage of $\mathrm{T}$ cells within the MLN normalizes, ${ }^{33}$ which may also explain why the percentages of 
a

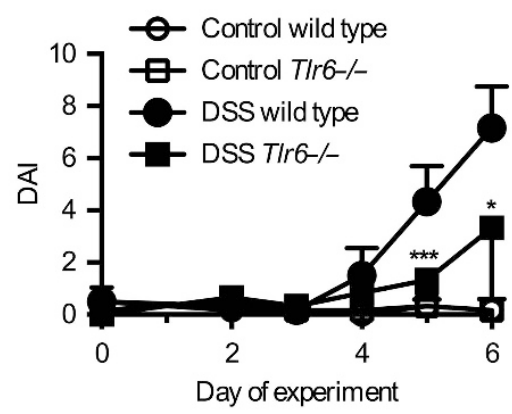

b

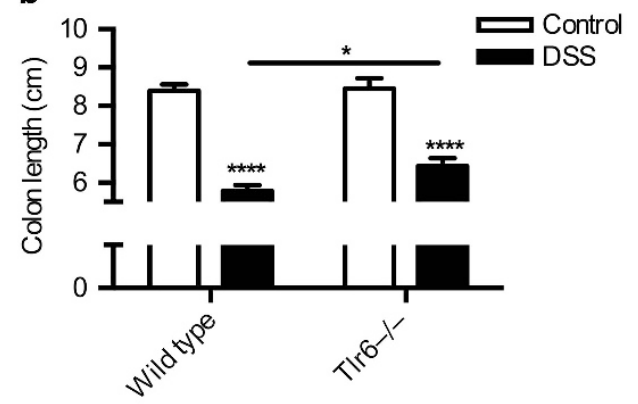

C
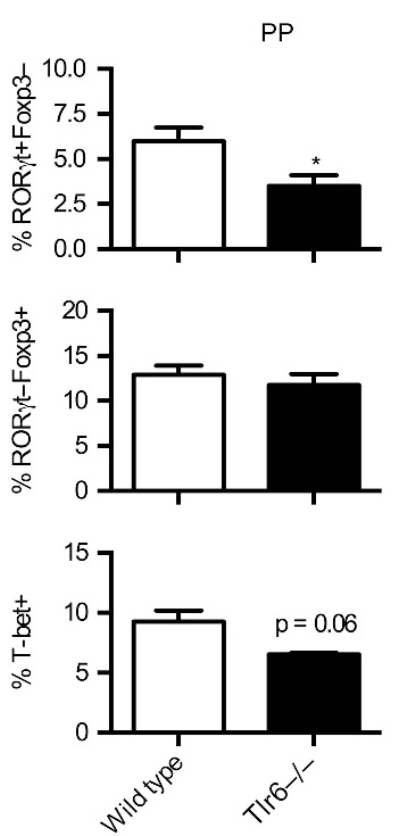

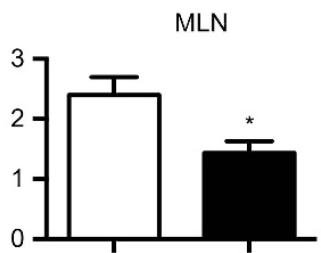

d

Tir6-/-
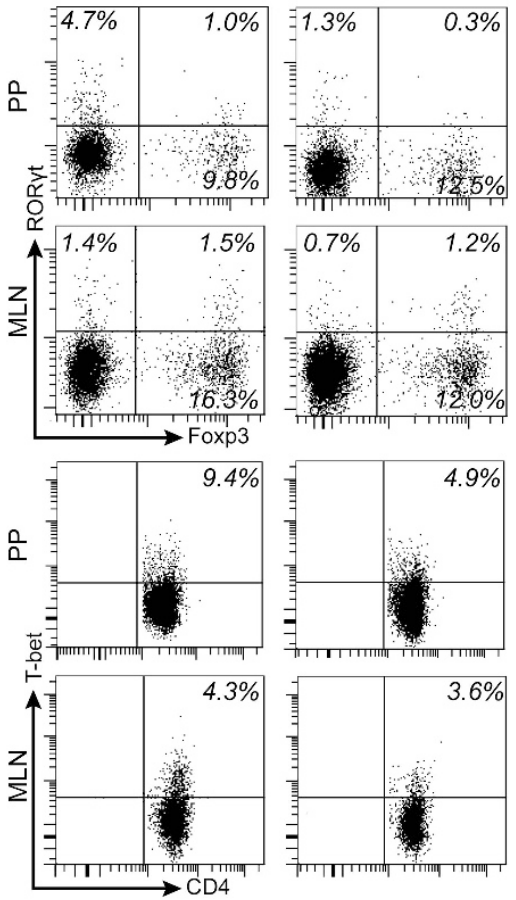

Figure 8 TIr6 - / - mice have reduced Th1 and Th17 responses and are protected from colitis. (a) Disease activity index (DAI) is shown for healthy controls and dextran sodium sulfate (DSS)-treated wild-type and TIr6 - / - mice $(n=6)$. (b) In the same mice, colon lengths were measured at sacrifice (day 7 after start of DSS). (c) Transcription factor staining is shown for CD4 + T cells from the gut-associated lymphoid tissue (GALT) for the mice in the above experiment treated with DSS. (d) Representative FACS plots are shown for the data presented in c. Data are given as mean + s.e.m. $P$-values considered as significant are indicated as ${ }^{\star}<0.05,{ }^{\star \star}<0.01,{ }^{\star \star *}<0.001$, and ${ }^{\star * \star *}<0.0001$. MLN, mesenteric lymph node; PPs, Peyer's patches.

cytokine-expressing $\mathrm{T}$ cells was so low in our intracellular cytokine staining assay.

Our results point to TLR6 being an important driver of Th1 and Th17 responses in the GALT. This is supported by both in vitro and in vivo evidence. Moreover, the fact that $R O R C$ and TLR6 mRNA levels are correlated in human intestine and that stimulations of human PBMCs mimic the murine results, suggests a similar relationship between TLR6 and proinflammatory $\mathrm{T}$-cell polarization in humans. As the reduction of Th1/Th17 responses in IBD is a prime goal for therapy, TLR6 could be a potential target for future IBD treatments.

\section{METHODS}

Animals. Female C57BL/6 mice for the oral TLRL study and for the in vitro experiments were purchased from Charles River Laboratories (Maastricht, The Netherlands). The mice were used at 8-12 weeks of age and were housed under standard conditions in the animal facilities at Utrecht University. Breeding pairs of Tlr6 - / - mice were obtained from Shizuo Akira (Osaka University). Male and female Tlr6 - / mice used both in vivo and in vitro were bred and kept in standard conditions at the Central Animal Facility of the Radboud University Nijmegen Medical Centre. Sex and aged-matched C57BL/6 controls used in the Tlr6-/ - in vivo experiment were bred in the same locale as the Tlr6-/- mice.

Experimental colitis. Experimental colitis was induced in all mice by adding $1.5 \%(\mathrm{w} / \mathrm{v})$ DSS (MP Biomedicals LLC, Illkirch, France) to the drinking water of the mice for 6 days, starting at day 1 of the experiment. Mice were sacrificed on either day 7 or 14 after starting DSS, depending on the experiment. Individual mice were considered a single experimental unit.

Oral gavages for TLRLs and OVA administration were performed on day 4, 5, and 6 to coincide with the developing intestinal inflammation. Each gavage contained $400 \mu \mathrm{g}$ endotoxin-free OVA (Hyglos GmBH, Bernried am Starnberger See, Germany) and $80 \mu \mathrm{g}$ of 
a

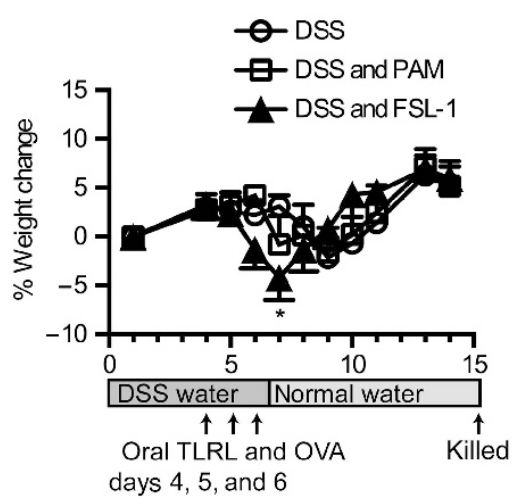

b

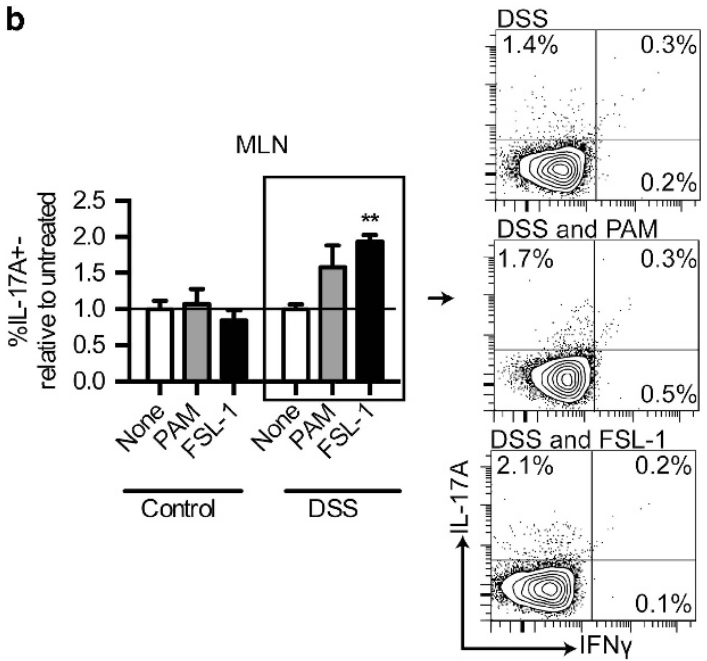

C

MLN
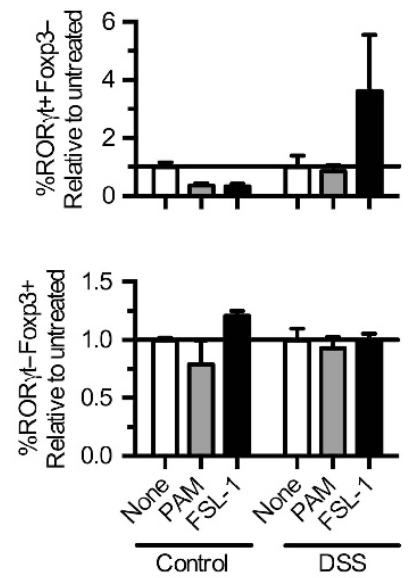

Spleen

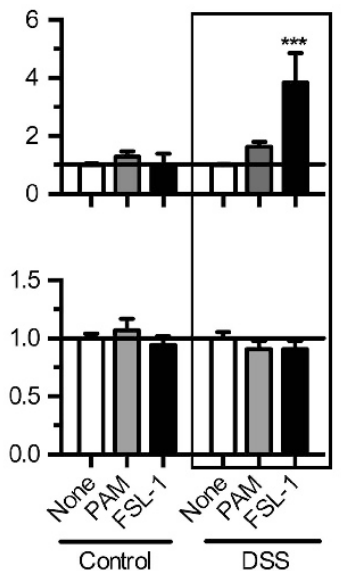

DSS

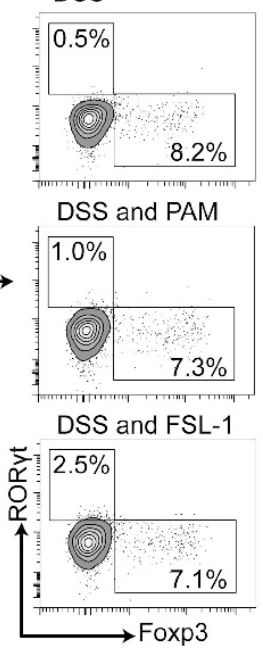

Figure 9 Oral FSL-1 worsens colitis and increases the Th17 response. Mice were administered regular water or dextran sodium sulfate (DSS) water for 6 days. On day 4,5 , and 6 , mice were given oral TLRLs combined with the tracking antigen ovalbumin (OVA). One week after stopping DSS, the mice were sacrificed $(n=5)$. (a) Percent weight gain of the mice over time relative to starting weight. Data are shown as the mean of each day $+/-$ s.e.m. The experimental design is shown under the weight graph. (b) Intracellular cytokine staining on CD4-gated mesenteric lymph node (MLN) cells isolated from the in vivo experiment. Data are presented as relative values of the mean percentage staining found in the untreated group (the group not receiving TLRL treatment). FACS plots on the right show representative staining of the DSS samples. (c) MLN and spleen cell cultures were analyzed for percentages of ROR $\gamma \mathrm{t}+$ Foxp3 - (Th17) and ROR $\gamma \mathrm{t}$-Foxp3 + (Treg) T-cell populations in CD4 + T cells after $48 \mathrm{~h}$ of anti-CD3 stimulation. Data are presented in the same manner as $\mathbf{b}$. Representative FACS plots on the right show examples of spleen data. Data are shown as the mean + s.e.m. $P$-values considered as significant are indicated as ${ }^{*}<0.05,{ }^{* \star}<0.01,{ }^{* \star *}<0.001$, and ${ }^{* \star \star *}<0.0001$.

either Pam3CSK4 or FSL-1 (both from EMC microcollections, Tuebingen, Germany) in $500 \mu \mathrm{l}$ saline solution. Both FSL-1 and Pam3CSK4 are synthetic lipopeptides. Control animals were administered saline only.

The disease activity index of colitis was determined by combining the scores collected from the weight measurement, rectal condition, feces condition, and the detectable presence of blood in the feces. The disease activity index was between 0 and 11 for each mouse. The loss of weight was scored as follows relative to starting weight: $0,0-2.5 \%$ weight loss; $1,2.5-$ $5 \%$ weight loss; $2,5-10 \%$ weight loss; $3,10-15 \%$ weight loss; and $4,>15 \%$ weight loss. The feces condition score was scored as follows: 0 , normal; 1 , soft with normal form; 2 , loss of form/diarrhea; and 3, no feces produced. The rectal condition score was determined as follows: 0 , normal; 1 , irritation present; 2, mucus and/or swelling; and 3, visible blood. Fecal blood was tested with a Colo-rectal test kit (Axon Lab AG, Stuttgart, Germany). Fecal blood was scored as follows: 0, no blood; 1, blood.
Messenger RNA expression analysis. The human intestinal tissue samples in this study were obtained from surgical resection specimens and include pairs of macroscopically inflamed and normal-appearing (non-inflamed) mucosa from patients with Crohn's disease $(n=5)$ and ulcerative colitis $(n=5)$, both clinically and histologically confirmed, with normal tissue from patients with a colorectal carcinoma, at least $10 \mathrm{~cm}$ from the tumor, as controls. Details on the tissue specimens and patient characteristics are described in a previous study as well as the methods of total RNA isolation. ${ }^{34}$

For the murine colon samples, the colons were divided into two equal sections: proximal and distal. The total RNA was isolated using the RNAeasy kit (Qiagen, Germantown, MD) and, subsequently, reverse transcribed into cDNA using the iScript cDNA synthesis kit (BioRad, Hercules, CA).

Real-time PCR was performed using iQ SYBR Green super mix kit (BioRad) with the CFX 96 Real-time system (BioRad). Messenger RNA 
for ribosomal protein S13 (RPS13) was used as the internal control in mice, and glyceraldehyde 3-phosphate dehydrogenase (GAPDH) mRNA was used as the internal control in the human samples. The primers used for the human real-time PCR were obtained from SA Biosciences (Frederick, MD). The primer sequences used for the mouse studies were as follows: Tlr $6 \mathrm{fwd}$ : $5^{\prime}$ GACTCTCCCACAAC AGGATACG 3', Tlr6 rev: $5^{\prime}$ TCAGGTTGCCAAATTCCTTACAC 3', Rps13 fwd: 5' GTCCGAAAGCACCTTGAGAG 3', Rps13 rev: $5^{\prime}$ AGCAGAGGCTGTGGATGACT $3^{\prime}$. The final data for the target samples were normalized against the internal control GAPDH in the human samples and Rps13 in the mouse samples. The relative mRNA expression values were calculated using Bio-Rad CFX manager V1.6.

Immunofluorescence. Cryostat sections $(5 \mu \mathrm{m})$ of the intestinal tissues of CD patients $(n=5)$, UC patients $(n=5)$ and normal tissue from patients with a colorectal carcinoma $(n=5)$ were cut, fixed in icecold acetone for $10 \mathrm{~min}$, blocked with $5 \%$ goat serum in $1 \%$ BSA/PBS (bovine serum albumin/phosphate-buffered saline) and afterwards incubated with rabbit-anti-TLR6 (1:125, Novus Biologicals, Cambridge, UK, NBP1-54336) in 1\% BSA/PBS overnight at $4{ }^{\circ} \mathrm{C}$. After subsequent washings with $\mathrm{PBS}$, the antibodies were visualized by incubation with goat-anti-rabbit-Alexa568 (1:400, Invitrogen, Breda, The Netherlands) in $1 \%$ BSA/PBS for $1 \mathrm{~h}$ at room temperature. Counterstaining was done with Hoechst 33,342 (Sigma Aldrich Chemie BV, Zwijndrecht, The Netherlands) for $5 \mathrm{~min}$ at room temperature and slides were sealed with Prolong gold anti-fade reagent (Invitrogen). Photomicrographs were taken at room temperature with an Olympus BX-60 microscope with a $\times 40 / 0.75$ na objective lens equipped with a Leica DFC425 C camera and controlled with LAS software 4.0 .

Ex vivo T-cell stimulation and PBMC culture. PPs, MLN, and splenocytes were isolated from mice. Cells were re-stimulated with either $25 \mu \mathrm{g} \mathrm{ml}^{-1}$ endotoxin-free OVA (Hyglos $\mathrm{GmBH}$ ) or $2 \mu \mathrm{g} \mathrm{ml}^{-1}$ anti-CD3 (eBioscience, San Diego, CA) with or without Pam3CSK4 or FSL-1 (4 $\mu \mathrm{g} \mathrm{ml}^{-1}$; EMC microcollections) and cultured with RPMI medium (Roswell Park Memorial Institute medium, Life Technologies, Paisley, Scotland) supplemented with 1 unit per $\mathrm{ml}$ penicillin, $1 \mu \mathrm{g} \mathrm{ml}^{-1}$ streptomycin, $50 \mu \mathrm{M} \beta$-mercaptoethanol, and 5\% FCS in 96well round-bottom plates at a concentration of $10^{5}$ cells per well. During the long stimulation, cells were incubated for 7 days before restimulation with PMA/ionomycin (Sigma). Otherwise, cells were incubated for $48 \mathrm{~h}$, after which, supernatants were collected; cells were harvested and stained with fluorescently labeled antibodies.

Human PBMCs were cultured in RPMI medium supplemented with 1 unit per ml penicillin, $1 \mu \mathrm{g} \mathrm{ml}^{-1}$ streptomycin, $1 \mathrm{~mm}$ pyruvate, $50 \mu \mathrm{g} \mathrm{ml}^{-1}$ gentamicin, and $2.5 \%$ FCS in 96-well round-bottom plates at a concentration of $10^{5}$ cells per well. Similarly to the murine experiments, the cells were incubated for $48 \mathrm{~h}$ with anti-CD3 $\left(1 \mu \mathrm{g} \mathrm{ml}^{-1}\right.$; eBioscience) with or without TLRLs (Pam3CSK4 or FSL-1, $4 \mu \mathrm{g} \mathrm{ml}^{-1}$; EMC microcollections). Upon completion of the incubation, the supernatants were collected and the cells harvested for FACS staining.

Flow cytometry. Intracellular cytokine staining was performed on either fresh or cultured cells after $5 \mathrm{~h}$ stimulation with PMA/Ionomycin (Sigma) and Brefeldin A (eBioscience). Cells were then stained with antibodies for CD4, IFN $\gamma$, IL-17A, IL-10, and IL-4 (all antibodies from eBioscience) using the Foxp3 intracellular staining kit (eBioscience). To prevent background staining, cells were first incubated with unlabeled anti-CD16/32 (eBioscience) for $15 \mathrm{~min}$ on ice as suggested in the manufacturer's protocol. Fixed samples were kept at $4{ }^{\circ} \mathrm{C}$ until reading with the flow cytometer.

Transcription factor expression was measured in murine cells or PBMCs by performing a surface stain with anti-CD4 and anti-CD69 and then staining intracellularly for Foxp3, T-bet, and ROR $\gamma \mathrm{t}$. All antibodies and the Foxp3 intracellular staining reagents were obtained from eBioscience. Before the surface stain and again during the intracellular stain, samples were blocked with unlabeled anti-human/mouse CD16/32 (eBioscience) for $15 \mathrm{~min}$ on ice. Fixed samples were kept at $4{ }^{\circ} \mathrm{C}$ until reading with the flow cytometer. All samples were read on a FACSCanto II flow cytometer (BD Biosciences, San Jose, CA) and analysis of the flow cytometry data was performed using BD FACSDiva software (BD Biosciences).

Cytokine measurements. Isolated supernatants were analyzed for cytokine production by using either the human or mouse BD Cytometric Bead Array Th1/Th2/Th17 kits (BD Biosciences) and the mouse/human TGF $\beta$ Ready-Set-Go! ELISA from eBioscience. Kits were used according to manufacturer's protocol. The bead array samples were read using a FACSCanto II flow cytometer (BD Biosciences). Data analysis was performed using the FCAP Array Analysis software and FCS Filter Software (Soft Flow Hungary Ltd., Pecs, Hungary).

Immunoblot. Intestinal tissues were weighed $\left(100 \mathrm{mg} \mathrm{ml}^{-1}\right)$ and homogenized in radioimmunoprecipitation assay buffer containing protease inhibitors and EDTA (Thermo Fisher Scientific, Rockford, IL) using a Precellys 24 tissue homogenizer (Bertin Technologies, Montigny-le-Bretonneux, France) for four times $10 \mathrm{~s}$ at 6,000 rpm with a minimum $5 \mathrm{~min}$ cooling period on ice in between. Afterwards, samples were centrifuged for $15 \mathrm{~min}$ at $14,000 \mathrm{rpm}$ and the supernatant was transferred to a clean tube. Homogenates were separated on 4-20\% (w/v) SDS gels (BioRad) and blotted to nitrocellulose membranes (Millipore, Billerica, MA). Membranes were blocked for $2 \mathrm{~h}$ with $5 \%$ milk proteins in PBS $/ 0.1 \%$ Tween- 20 and subsequently incubated with rabbit-anti-mouse TLR6 (Sigma, SAB1300203) in PBS/ $2 \%$ milk/0.1\% Tween-20 overnight at $4{ }^{\circ} \mathrm{C}$. After incubation, membranes were washed three times with $\mathrm{PBS} / 2 \%$ milk/0.1\% Tween20 , incubated with goat-anti-rabbit-horse radish peroxidase (Dako, Heverlee, The Netherlands) in PBS/2\% milk/0.1\% Tween-20, treated with commercial ECL reagents (Amersham Biosciences, Roosendaal, The Netherlands) and finally exposed to photographic film. Afterwards, blots were stripped with stripping buffer (Thermo Fisher Scientific) and reprobed with rabbit-anti- $\beta$-actin (Cell Signaling Technology, Danvers, MA). The TLR6 staining appears as double bands and this is in accordance with the staining pattern depicted by the manufacturer.

Statistical analysis. Means with s.e.m. are represented in each graph. Statistical analysis was performed using GraphPad Prism version 6.0 for windows (GraphPad Software, San Diego, CA). Correlation significance was determined using the Pearson product-moment correlation coefficient. For comparisons between two groups, $T$-test or Mann-Whitney test were used depending on the distribution of the data. Comparisons between three or more groups were performed with either a one-way analysis of variance or repeated measures analysis of variance followed by the Bonferroni post test where appropriate. In cases of repeated, nonparametric data, the Friedman test followed by Dunn's multiple comparison post test was used. In the situation of two independent parameters, a two-way analysis of variance was applied (either regular or repeated measures) with the Bonferroni post test.

SUPPLEMENTARY MATERIAL is linked to the online version of the paper at http://www.nature.com/mi

\section{ACKNOWLEDGMENTS}

We would like to thank Gerard Hofman (Department of Pharmaceutical Sciences, Utrecht University) for his help with several animal procedures, Debby Smits (Central Animal Laboratory, Radboud University, Nijmegen Medical Centre) for her help in organizing animal experiments and Rob Bleumink (The Center for Cell Imaging, Faculty of Veterinary Medicine, Utrecht University) for his help with the fluorescent imaging. This study was performed and supported within the framework of Dutch Top Institute Pharma (project number D1-101). 


\section{DISCLOSURE}

The authors declared no conflict of interest.

(c) 2014 Society for Mucosal Immunology

\section{REFERENCES}

1. Takeuchi, O. et al. TLR6: a novel member of an expanding toll-like receptor family. Gene 231, 59-65 (1999).

2. Hajjar, A.M. et al. Cutting edge: functional interactions between toll-like receptor (TLR) 2 and TLR1 or TLR6 in response to phenol-soluble modulin. J. Immunol. 166, 15-19 (2001).

3. Takeuchi, O. et al. Discrimination of bacterial lipoproteins by Toll-like receptor 6. Int. Immunol. 13, 933-940 (2001).

4. Ozinsky, A. et al. The repertoire for pattern recognition of pathogens by the innate immune system is defined by cooperation between toll-like receptors. Proc. Natl Acad. Sci. USA 97, 13766-13771 (2000).

5. Depaolo, R.W. et al. Toll-like receptor 6 drives differentiation of tolerogenic dendritic cells and contributes to LcrV-mediated plague pathogenesis. Cell Host Microbe 4, 350-361 (2008).

6. DePaolo, R.W., Kamdar, K., Khakpour, S., Sugiura, Y., Wang, W. \& Jabri, B. A specific role for TLR1 in protective $T(H) 17$ immunity during mucosal infection. J. Exp. Med. 209, 1437-1444 (2012).

7. Pot, C., Apetoh, L. \& Kuchroo, V.K. Type 1 regulatory T cells (Tr1) in autoimmunity. Semin. Immunol. 23, 202-208 (2011).

8. Moreira, A.P. et al. The protective role of TLR6 in a mouse model of asthma is mediated by IL-23 and IL-17A. J. Clin. Invest. 121, 4420-4432 (2011).

9. Miossec, P. \& Kolls, J.K. Targeting IL-17 and TH17 cells in chronic inflammation. Nat. Rev. Drug Discov. 11, 763-776 (2012).

10. Ahern, P.P. et al. Interleukin-23 drives intestinal inflammation through direct activity on T cells. Immunity 33, 279-288 (2010).

11. Jostins, L. et al. Host-microbe interactions have shaped the genetic architecture of inflammatory bowel disease. Nature 491, 119-124 (2012).

12. Kleinschek, M.A. et al. Circulating and gut-resident human Th17 cells express CD161 and promote intestinal inflammation. J. Exp. Med. 206 , 525-534 (2009).

13. Eastaff-Leung, N., Mabarrack, N., Barbour, A., Cummins, A. \& Barry, S. Foxp3 + regulatory Tcells, Th17 effector cells, and cytokine environment in inflammatory bowel disease. J. Clin. Immunol. 30, 80-89 (2010).

14. Doherty, G.A. et al. CD73 is a phenotypic marker of effector memory Th17 cells in inflammatory bowel disease. Eur. J. Immunol. 42, 3062-3072 (2012).

15. Olsen, T., Rismo, R., Cui, G., Goll, R., Christiansen, I. \& Florholmen, J. TH1 and $\mathrm{TH} 17$ interactions in untreated inflamed mucosa of inflammatory bowel disease, and their potential to mediate the inflammation. Cytokine 56, 633-640 (2011).

16. Ghoreschi, K., Laurence, A., Yang, X.P., Hirahara, K. \& O'Shea, J.J. Thelper 17 cell heterogeneity and pathogenicity in autoimmune disease. Trends Immunol. 32, 395-401 (2011).

17. Fong, D.J., Hogaboam, C.M., Matsuno, Y., Akira, S., Uematsu, S. \& Joshi, A.D. Toll-like receptor 6 drives interleukin-17A expression during experimental hypersensitivity pneumonitis. Immunology 130, 125-136 (2010).

18. Pabst, R., Durak, D., Roos, A., Luhrmann, A. \& Tschernig, T. TLR2/6 stimulation of the rat lung: effects on lymphocyte subsets, natural killer cells and dendritic cells in different parts of the air-conducting compartments and at different ages. Immunology 126, 132-139 (2009).

19. Oberg, H.H., Ly, T.T., Ussat, S., Meyer, T., Kabelitz, D. \& Wesch, D. Differential but direct abolishment of human regulatory $\mathrm{T}$ cell suppressive capacity by various TLR2 ligands. J. Immunol. 184, 4733-4740 (2010).

20. Nyirenda, M.H. et al. TLR2 stimulation drives human naive and effector regulatory $\mathrm{T}$ cells into a Th17-like phenotype with reduced suppressive function. J. Immunol. 187, 2278-2290 (2011).

21. Zheng, B., Morgan, M.E., van de Kant, H.J., Garssen, J., Folkerts, G. \& Kraneveld, A.D. Transcriptional modulation of pattern recognition receptors in acute colitis in mice. Biochim. Biophys. Acta 1832, 2162-2172 (2013).

22. Ivanov, I.I. et al. The orphan nuclear receptor RORgammat directs the differentiation program of proinflammatory IL-17 + Thelper cells. Cell 126, 1121-1133 (2006)

23. Ruan, Q. et al. The Th17 immune response is controlled by the Rel-RORgamma-RORgamma T transcriptional axis. J. Exp. Med. 208, 2321-2333 (2011).

24. Kimura, A. \& Kishimoto, T. IL-6: regulator of Treg/Th17 balance. Eur. J. Immunol. 40, 1830-1835 (2010).

25. Gao, Z. et al. Synergy between IL-6 and TGF-beta signaling promotes FOXP3 degradation. Int. J. Clin. Exp. Pathol. 5, 626-633 (2012).

26. Kryczek, I. et al. Cutting edge: IFN-gamma enables APC to promote memory Th17 and abate Th1 cell development. J. Immunol. 181, 5842-5846 (2008).

27. Komai-Koma, M., Jones, L., Ogg, G.S., Xu, D. \& Liew, F.Y. TLR2 is expressed on activated Tcells as a costimulatory receptor. Proc. Natl Acad. Sci. USA 101, 3029-3034 (2004).

28. Slifka, M.K. \& Whitton, J.L. Antigen-specific regulation of T cell-mediated cytokine production. Immunity 12, 451-457 (2000).

29. Walker, J.A., Barlow, J.L. \& McKenzie, A.N. Innate lymphoid cells—how did we miss them?. Nat. Rev. Immunol. 13, 75-87 (2013).

30. Li, H., Wojciechowski, W., Dell'Agnola, C., Lopez, N.E. \& Espinoza-Delgado, I. IFN-gamma and T-bet expression in human dendritic cells from normal donors and cancer patients is controlled through mechanisms involving ERK-1/2-dependent and IL-12-independent pathways. J. Immunol. 177, 3554-3563 (2006).

31. Gessani, S. \& Belardelli, F. IFN-gamma expression in macrophages and its possible biological significance. Cytokine Growth Factor Rev. 9, 117-123 (1998).

32. Bradley, L.M., Dalton, D.K. \& Croft, M. A direct role for IFN-gamma in regulation of Th1 cell development. J. Immunol. 157, 1350-1358 (1996).

33. Hall, L.J., Faivre, E., Quinlan, A., Shanahan, F., Nally, K. \& Melgar, S. Induction and activation of adaptive immune populations during acute and chronic phases of a murine model of experimental colitis. Dig. Dis. Sci. 56, 79-89 (2011).

34. Gao, Q. et al. Expression of matrix metalloproteinases-2 and -9 in intestinal tissue of patients with inflammatory bowel diseases. Dig. Liver Dis. 37, 584-592 (2005).

(c) (1) () $\Theta$ This work is licensed under the Creative Commons Attribution-NonCommercial-No Derivative Works 3.0 Unported License. To view a copy of this license, visit http:// creativecommons.org/licenses/by-nc-nd/3.0/ 